\title{
STATUS OF TALENT MANAGEMENT PRACTICES IN INSTITUTIONS OF HIGHER LEARNING IN NIGERIA
}

\author{
Abdulkarim S. Praise, American University of Nigeria, Nigeria \\ Osho Ajayi, American University of Nigeria, Nigeria
}

dx.doi.org/10.18374/JABE-20-3.2

\begin{abstract}
There is a growing concern over the deploring state of quality education, institutional ranking, quality of graduates, and brain drain of students and talents which portends looming danger in the educational sector in Nigeria. This study aimed at investigating the status of Talent Management Practice in Institutions of Higher Learning in Nigeria. The researchers employed a quantitative survey design. A structured questionnaire was used to collect empirical data. Data was cleaned and analyzed using tables and percentages. The findings of the study showed that talent management practices in Institutions of Higher Learning in Nigeria is still very poor, low and work in progress. The implication of this position is that Institutions of Higher Learning must continue to invest in talent management by implementing developmental programs for teaching and administrative talents, recruit and select talents meritoriously, maintain research and teaching enabling environment as part of the operational culture to sustain competitive advantage.
\end{abstract}

Keywords: Talent Management Practices, Competitive Advantage, Status of Talent Management, Institution of Higher Learning. 